Marquette University

e-Publications@Marquette

\title{
A Naturalistic Study of the Associations between Changes in Alcohol Problems, Spiritual Functioning and Psychiatric Symptoms
}

Melissa L. Miller

Marquette University

Stephen M. Saunders

Marquette University, stephen.saunders@marquette.edu

Follow this and additional works at: https://epublications.marquette.edu/psych_fac

Part of the Psychology Commons

\section{Recommended Citation}

Miller, Melissa L. and Saunders, Stephen M., "A Naturalistic Study of the Associations between Changes in Alcohol Problems, Spiritual Functioning and Psychiatric Symptoms" (2011). Psychology Faculty Research and Publications. 54.

https://epublications.marquette.edu/psych_fac/54 


\title{
A Naturalistic Study of the Associations between Changes in Alcohol Problems, Spiritual Functioning, and Psychiatric Symptoms
}

\author{
Melissa L. Miller \\ Department of Psychology, Marquette University \\ Milwaukee, WI \\ Stephen M. Saunders \\ Department of Psychology, Marquette University \\ Milwaukee, WI
}

\begin{abstract}
The study evaluated how spiritual and religious functioning (SRF), alcohol-related problems, and psychiatric symptoms change over the course of treatment and follow-up. Problem drinkers ( $n=55$, including 39 males and 16 females) in outpatient treatment were administered questionnaires at pretreatment, post-treatment, and follow up, which assessed two aspects of SRF (religious well-being and existential well-being), two aspects of alcohol

[Citation Journal/Monograph Title, Vol XX, No. XX (m yyyy): pg. XX-XX. DOI. This article is @ [Publisher's Name] and permission has been granted for this version to appear in e-Publications@Marquette. [Publisher's Name] does not grant permission for this article to be further copied/distributed or hosted elsewhere without the express permission from [Publisher's Name].]
\end{abstract}


misuse (severity and consequences), and two aspects of psychiatric symptoms (depression and anxiety). Significant improvements in SRF, psychiatric symptoms and alcohol misuse were observed from pretreatment to follow-up. Although SRF scores were significantly correlated with psychiatric symptoms at all three time points, improvement in the former did not predict improvement in the latter. When measured at the same time points, SRF scores were not correlated with the measures of alcohol misuse. However, improvement in SRF (specifically in existential well-being) over the course of treatment was predictive of improvement in the alcohol misuse measures at follow-up. These results suggest that the association between SRF, emotional problems, and alcohol misuse is complex. They further suggest that patients who improve spiritual functioning over the course of treatment are more likely to experience improvement in drinking behavior and alcohol-related problems after treatment has ended.

Keywords: Alcohol, Spirituality, Psychiatric, Psychotherapy

The advent of a biopsychosocial approach to understanding the development and treatment of alcohol-related problems has led to an exploration of how spiritual and religious beliefs and practices affect alcohol-related attitudes and behaviors, including alcohol use problems. A large number of studies have established that there is a negative correlation between alcohol use and measures of spirituality in both non-problematic alcohol consumption (e.g., Engs, Hanson, \& Diebold, 1996) and alcohol misuse (e.g., Hardesty, \& Kirby, 1995) for both adult and adolescent populations (e.g., Benda, 1995). Various aspects of religiosity have been found to be correlated with alcohol use, including religious affiliation, commitment to beliefs, and level of religious activity (e.g., Engs et al., 1996; Kendler, Gardner, \& Prescott, 1997). In the United States, the treatment of alcohol problems has long been associated with spirituality and religiousness. Twelve-step programs, exemplified by Alcoholics Anonymous, explicitly assert that improving spirituality is essential to recovery, and studies suggest that these programs are effective (Montgomery, Miller, \& Tonigan, 1995; Project MATCH Research Group, 1997). Other studies have likewise found that increased spirituality or religiosity is associated with recovery (e.g., Robinson, Cranford, Webb, \& Brower, 2007; Zemore \& Kaskutas, 2004).

There are several ways in which spirituality and religion might be associated with alcohol misuse. First, spiritual and religious behaviors can help with stress. Pargament and others (e.g., Pargament, Koenig, Tarakeshwar, \& Hahn, 2004; Tarakeshwar, 
Pearce, \& Sikkema, 2005) have demonstrated that religiously-based coping can either alleviate or exacerbate the effects of stressful events. Second, spirituality and religion may promote healthy behaviors and emotions (e.g., Waite, Hawks, \& Gast, 1999). For example, two different surveys have shown an inverse relationship between measures of spiritual and religious behaviors (e.g., religious service attendance) and indicators of depression (Chatters, Bullard, Taylor, Woodward, Neighbors, \& Jackson, 2008; Mofidi, DeVellis, Blazer, DeVellis, Panter, \& Jordan, 2006). Moreover, some religions expressly forbid alcohol consumption, and almost all state that alcohol misuse is wrong. It may be that being active in spiritually-related behaviors promotes self-esteem and generates positive emotions, such as feelings of being loved and forgiven (e.g., Chatters, 2000). Finally, spiritual and religious behaviors typically entail fairly intensive formal and informal social activities, which are known to alleviate stress and to have palliative effects on psychological health (e.g., McCullough, Hoyt, Larson, Koenig, \& Thoresen, 2000).

A common theme to these putative mechanisms is that the attitudes and activities associated with spirituality and religion are associated with enhanced well-being and decreased psychiatric distress, which lead to less vulnerability to alcohol misuse (cf. Kessler, Nelson, McGonagle, Edlund, Frank, \& Leaf, 1996). However, there has been limited research into the association between measures of spirituality, psychiatric symptoms, and alcohol misuse. In one study, Zemore and Kaskutas (2004) found that measures of spirituality were associated with length of sobriety in patients being treated for alcoholrelated problems. Further analyses of the dataset indicated significant relationships between measures of spirituality and psychiatric severity, but not between psychiatric severity and length of sobriety (Polcin \& Zemore, 2004). In other words, it appeared that spirituality was having a direct effect (versus mediated by emotional distress) on sobriety.

In this study, we assessed patients in outpatient treatment for alcohol dependence prior to treatment, immediately after treatment, and at three months follow up. We attempted to evaluate the associations between changes that occur, over the course of treatment and a three month follow-up period, on measures of spiritual 
functioning, measures of psychiatric symptoms, and measures of alcohol use and alcohol-related problems.

In the following, we conceptualize religiosity as thoughts (including beliefs and values), feelings and behaviors that are specifically related to an organized and identifiable religion. We conceptualize spirituality more generally as thoughts, feelings or behaviors that entail a striving for understanding and relatedness to something transcendent (cf. Hill \& Pargament, 2003). We use the term "spiritual and religious functioning" (SRF) to include both spiritual and religious thoughts, feelings and behaviors.

In this study, we utilize a unique, but previously validated, approach to measuring SRF (S. M. Saunders, Wright \& Kuras, 2007). In many studies, SRF is measured by contrasting the person's score on an SRF scale to normative data (e.g., Bufford, Paloutzian \& Ellison, 1991). In others, scores on an SRF scale (such as the engagement in spiritual or religious behavior) are contrasted between different groups (e.g., Kendler et al., 1997). However, we believe that SRF is better considered an entirely subjective phenomenon, which can only be evaluated by the person, in idiosyncratic fashion, in comparison to a personal ideal. We consider such a comparison a more appropriate way to evaluate a person's SRF in terms of personal importance and adequacy and, in particular, any concern or distress that a person might have regarding his or her SRF. In a previous study, SRF was measured as the discrepancy between a person's ratings of "ideal" SRF and current SRF (S. M. Saunders et al., 2007). They showed that discrepancy scores for persons misusing alcohol were higher than those of control subjects. We utilize this means of measuring SRF in this study.

\section{Method}

\section{Participants}

Participants were recruited from two outpatient alcohol treatment centers in the Midwest. Eighty participants were enrolled in the study, including 22 females and 58 males with a mean age of 38.3 years $(S D=10.6)$. Of these participants, 56 completed both treatment 
and research protocols. Treatment entailed a three-month program consisting of both group and individual therapy focused on identifying precursors to drinking behavior, strategies for eliminating drinking, and addressing other problematic issues associated with excessive drinking. The research protocol included interviews at intake, posttreatment, and three months follow up. Of the 24 that did not complete all three interviews, nine dropped out of both treatment and the research project, whereas four dropped out of the research project (although they completed treatment, according to their self-report). Three could not be located, four were scheduled but did not show, and four were incarcerated after the first interview and could not attend subsequent interviews. Finally, one participant who completed treatment and the research protocol was dropped from the analyses due to inconsistent responses. This individual selected the first response choice for every item of every measure, which resulted in an inconsistent and invalid response pattern.

The 55 study participants were 39 males and 16 females, with a mean age of $38.5(S D=10.7)$ and $13.6(S D=2.3)$ mean years of education. The final sample was predominantly white $(n=48 ; 3$ African American; 2 Latino/Hispanic; 1 Native American; 1 Asian American). Regarding marital status, 18 were either married or remarried, 15 were separated or divorced, and 22 had never been married. Most had one or more children $(n=35)$. Fourteen participants stated that they were either unemployed or disabled, and the rest were either employed full-time $(n=37)$ or part-time $(n=4)$.

All participants were identified by the Structured Clinical Interview for the Diagnostic and Statistical Manual of Mental Disorders (SCID; 4th ed; First, Spitzer, Gibbon, \& Williams, 1996) as having a diagnosis of alcohol dependence. By self-report, the mean age at which the participants began "drinking regularly" was 19.6 (SD = 6.2), and the mean age at which the drinking problem developed was about six years later $(M=25.3, S D=9.5)$. Fifteen of the participants indicated that treatment had been mandated by the criminal justice system. Mood and anxiety disorders were also evaluated by the SCID, and five participants met criteria for a mood disorder only (dysthymia, bipolar disorder, or major depressive disorder), 11 met criteria for an anxiety disorder (panic disorder, a social or specific phobia, generalized anxiety disorder, obsessive compulsive disorder, or post-

[Citation Journal/Monograph Title, Vol XX, No. XX (m yyyy): pg. XX-XX. DOI. This article is (C [Publisher's Name] and permission has been granted for this version to appear in e-Publications@Marquette. [Publisher's Name] does not grant permission for this article to be further copied/distributed or hosted elsewhere without the express permission from [Publisher's Name].] 
traumatic stress disorder), and seven met criteria for both a mood and an anxiety disorder.

Comparisons of the 56 who did complete and the 24 who did not complete the research protocol indicated that the groups were not significantly different on any demographic attributes (e.g., gender) and that they had similar rates of mood (major depression, dysthymia and bipolar disorder) and anxiety disorders (PTSD, OCD, panic disorder, GAD and specific phobia) with the exception of social phobia. Those who completed treatment were more likely to be diagnosed with social phobia than drop-outs $\left(x^{2}=4.90, p<.05\right)$. The two groups were also similar with regard to alcohol use and alcohol-related consequences, as well as with respect to whether they were courtmandated to attend treatment. Regarding SRF measures, there was no difference in RWB Discrepancy between those who completed treatment and those who did not; however, those who completed treatment $(M=15.95, S D=13.33)$ reported significantly higher EWB Discrepancy scores at the first time point than those who dropped out $(M=7.1, S D=10.10), t(78)=2.89, p<.01$.

\section{Measures}

\section{Spiritual and religious functioning (SRF)}

Participants completed the Spiritual Well-Being Scale (SWBS; Bufford, Paloutzian, \& Ellison, 1991; Paloutzian \& Ellison, 1982), which has two 10-item subscales. The Religious Well Being (RWB) subscale contains explicit references to God and evaluates one's relationship with God (e.g., "I find much satisfaction in private prayer with God"), whereas the Existential Well Being (EWB) subscale evaluates one's sense of purpose and of life satisfaction (e.g., "I feel that life is a positive experience"). Participants rate agreement with each statement using a rating scale ranging from 1 ("strongly disagree") to 6 ("strongly agree"). Prior research indicates that the SWBS and its two subscales have good face validity and adequate construct validity, as well as adequate test-retest reliability and internal consistency (Bufford et al., 1991).

The study utilized the methodology for evaluating SRF developed by S. M. Saunders et al. (2007), who argued that "there are permission has been granted for this version to appear in e-Publications@Marquette. [Publisher's Name] does not grant permission for this article to be further copied/distributed or hosted elsewhere without the express permission from [Publisher's Name].] 
not and probably cannot be preferred or normative levels of spiritual and religious functioning" (p. 404). They suggested that measuring the discrepancy between what people report (via SRF questionnaires) is their current SRF and what they report would be their "ideal" SRF. Using that methodology, in this study, participants twice completed the SWBS. First, they indicated their agreement with each statement "currently or as things are for you now." Next, they completed the questionnaire by indicating "how much you would agree with a statement if things were the way you wanted." Items were worded identically except verb tenses, which were changed to reflect the difference between current and ideal states (e.g., "I feel that life is a positive experience" was changed to "I would feel that life is a positive experience"). To generate RWB Discrepancy and EWB Discrepancy scores, the difference between participants' "ideal" and "current" scores on the RWB and EWB scales was calculated. In a previous study (S. M. Saunders et al., 2007), both the "ideal" and "current" versions of the RWB and EWB were shown to have good internal consistency (ranging from .90 to .97) and test-retest reliability (.71 to .93), and RWB Discrepancy and EWB Discrepancy scores were shown to distinguish between problem drinkers and normal controls.

\section{Depression and anxiety symptoms}

The Brief Symptom Inventory (BSI) is a widely used measure of severity of psychiatric symptoms (Derogatis \& Spencer, 1982). Respondents rated each of 53 items with respect to "how you have been feeling during the past 7 days" on a 5-point scale from "not at all" $(=0)$ to "always" $(=4)$. The BSI comprises subscales, and this study used the depression (BSI Depression) and anxiety (BSI Anxiety) subscales only. The subscales have well-established internal and testretest reliability and validity (e.g., Boulet, 1991). Higher scores indicated higher amounts of depression or anxiety symptoms.

\section{Drinking severity and consequences}

The Alcohol Use Disorders Identification Test (AUDIT; Bohn, Babor, \& Kranzler, 1995) contains ten items that evaluate hazardous drinking behavior, including measures of alcohol consumption, potential alcohol dependence and alcohol-related problems (e.g., "How often during the last year have you been unable to remember what 
happened the night before because you had been drinking"). Total scores range from $0-40$, with scores greater than 8 indicating harmful drinking and scores above 13 (for women) and 15 (for men) indicating that a diagnosis of alcohol dependence is likely warranted. The AUDIT has good internal consistency and concurrent validity (e.g., Allen, Litten, Fertig, \& Babor, 1997), as well as high sensitivity and specificity (J. B. Saunders, Aasland, Babor, de la Fuente, \& Grant, 1993).

Alcohol-related negative consequences were evaluated using the Drinker Inventory of Consequences (DrInC; Miller, Tonigan, \& Longabaugh, 1995), which contains 45 items (e.g., "The quality of my work has suffered because of my drinking or drug use"). Each item was rated on the frequency or extent that the consequence occurred over the past three months $(0=$ "Never" through $5=$ "Almost every day"). The scale has high internal item consistency and good testretest reliability (Miller et al., 1995). For this study, the overall DrInC score was used and higher scores indicated higher amounts of consequences..

\section{Procedure}

Participants were recruited from outpatient treatment programs. Therapists informed clients of the opportunity to participate in a research project, and those who were interested contacted the research office. To determine if they were willing and eligible to be in the study, callers listened to an explanation of the study and were administered a brief demographic interview and the AUDIT over the phone. To be eligible for the study, callers had to be between ages 21 to 75 years, had to be able to read English at grade 6 level, needed to obtain a score of 8 or more on the AUDIT, and must have identified themselves as having "a drinking problem." Individuals were excluded if they identified a different drug as the primary problem. Potential participants who met criteria were informed about the requirements of the study, as well as incentives for completing the three research interviews. Any who gave informed consent were entered into the study and the first research interview was scheduled. Participants were paid $\$ 50$ for each of the first two interviews and $\$ 75$ for the third interview.

[Citation Journal/Monograph Title, Vol XX, No. XX (m yyyy): pg. XX-XX. DOI. This article is @ [Publisher's Name] and permission has been granted for this version to appear in e-Publications@Marquette. [Publisher's Name] does not grant permission for this article to be further copied/distributed or hosted elsewhere without the express permission from [Publisher's Name].] 


\section{Analyses}

The sample size was not sufficient to examine changes in SRF, psychiatric symptoms and alcohol measures simultaneously. We first examined the correlations between these measures. We then utilized repeated measures ANOVA to determine how each of these measures changed over the course of treatment and follow-up. Regression analyses were conducted to examine the association between changes in measures of SRF and improvement on alcohol measures over the course of treatment and three-month follow-up. We then conducted similar analyses to examine whether changes in SRF were associated with changes in psychiatric symptoms.

\section{Results}

\section{Associations Among Measures of Drinking, Psychiatric Symptoms and SRF}

There were two measures of each of the constructs of interest (alcohol use, psychiatric symptoms and SRF), and the correlations between the measures were calculated. The correlations between the AUDIT and the DrInC at pre-treatment, post-treatment and follow-up, respectively, were $.69, .48$ and $.54\left(p^{\prime} s<.001\right)$. The correlations between the BSI Depression and anxiety scores at these three time points were also high $\left(.78, .76\right.$ and $\left..78, p^{\prime} s<.001\right)$, as were the correlations between the EWB Discrepancy and RWB Discrepancy scores $\left(.77, .53\right.$ and $\left..67, p^{\prime} s<.001\right)$.

The correlations between the psychiatric measures and the drinking measures were computed at pre-treatment, post-treatment and follow-up. Because of the large number of calculations, alpha was set at .004. At these respective time points, the AUDIT was not significantly correlated with the BSI Depression scale ( $r^{\prime} s$ $=.27, .36, .21$, respectively) nor the BSI Anxiety scale ( $r$ 's $=.20, .33, .35)$. The DrInC was significantly correlated with the BSI Depression scale at pre-treatment and post-treatment (.40 and $.41, p$ $<.004)$, but not at follow-up $(r=.29, \mathrm{~ns})$. The DrInC was not significantly correlated with the BSI Anxiety subscale at pre-treatment

[Citation Journal/Monograph Title, Vol XX, No. XX (m yyyy): pg. XX-XX. DOI. This article is @ [Publisher's Name] and permission has been granted for this version to appear in e-Publications@Marquette. [Publisher's Name] does not grant permission for this article to be further copied/distributed or hosted elsewhere without the express permission from [Publisher's Name].] 
NOT THE PUBLISHED VERSION; this is the author's final, peer-reviewed manuscript. The published version may be accessed by following the link in the citation at the bottom of the page.

$(r=.35)$ nor post-treatment $(r=.30)$, but was at follow-up $(r=.38$, $p<.004)$.

The correlations between the measures of SRF and the measures of drinking and psychiatric symptoms at the three time points are shown in Table 1. Because of the large number of calculations, to be significant, alpha was set at .003. We examined, in particular, the correlations between the measures at the three time points. The RWB Discrepancy scores were significantly positively correlated with BSI Depression scores at pre-treatment and follow-up, indicating that higher discrepancy scores were associated with higher levels of depression. However, the RWB Discrepancy scores were not significantly correlated with the other measures of either drinking problems or psychiatric symptoms. The EWB Discrepancy scores were not significantly correlated with the drinking measures (after the Bonferroni correction), but they were significantly positively correlated with the measures of depression and anxiety at all three time points (see Table 1).

Table 1. Correlations Between Measures of Spirituality, Drinking and Psychiatric Symptoms.

Spirituality Measures

RWB Discrepancy EWB Discrepancy

Pre Post Follow Pre Post Follow

Drinking Measures

$\begin{array}{llllllll}\text { AUDIT } & \text { Pre } & .25 & .06 & .04 & .32 & .17 & .13 \\ & \text { Post } & .05 & .01 & .11 & .09 & .30 & .20 \\ & \text { Follow } & .07 & .07 & .22 & .05 & .36 & .25 \\ \text { DrInC } & \text { Pre } & .21 & -.02 & -.03 & .34 & .09 & .11 \\ & \text { Post } & .21 & .11 & .04 & .26 & .21 & .12 \\ & \text { Follow } & .19 & .16 & .19 & .11 & .34 & .27\end{array}$

[Citation Journal/Monograph Title, Vol XX, No. XX (m yyyy): pg. XX-XX. DOI. This article is @ [Publisher's Name] and permission has been granted for this version to appear in e-Publications@Marquette. [Publisher's Name] does not grant permission for this article to be further copied/distributed or hosted elsewhere without the express permission from [Publisher's Name].] 
NOT THE PUBLISHED VERSION; this is the author's final, peer-reviewed manuscript. The published version may be accessed by following the link in the citation at the bottom of the page.

Spirituality Measures

RWB Discrepancy EWB Discrepancy

Pre Post Follow Pre Post Follow

Psychiatric Symptoms Measures

$\begin{array}{llllllllll}\text { BSI Depression Pre } & .42^{*} & .08 & .03 & .51^{*} & .03 & .03 \\ & \text { Post } & .07 & .13 & .24 & .07 & .48^{*} & .35 \\ & \text { Follow } & .18 & .17 & .40^{*} & .18 & .40^{*} & .53^{*} \\ \text { BSI Anxiety } & \text { Pre } & .30 & .01 & -.02 & .51^{*} & .12 & .15 \\ & \text { Post } & .07 & .05 & .11 & .17 & .41^{*} & .28 \\ & & & & & & & & & \\ & \text { Follow } & .18 & .07 & .18 & .33 & .46^{*} & .47^{*}\end{array}$

Note: Pre $=$ Pre-treatment; Post $=$ Post-treatment; Follow $=$ Follow up. ${ }^{*} p<.003$.

\section{Changes in Drinking, Psychiatric Symptoms, and SRF}

A series of repeated-measures ANOVAs and paired-samples ttests were computed to examine changes in the RWB Discrepancy, EWB Discrepancy, AUDIT, DrInC, BSI Depression, and BSI Anxiety scores from pre-treatment to post-treatment to follow-up. The results are displayed in Table 2. Values with sphericity assumed are reported for RWB Discrepancy and DrInC scores. However, Mauchly's test of sphericity was significant for the EWB Discrepancy, AUDIT, BSI Depression, and BSI Anxiety scores, so the Huynh-Feldt epsilon was utilized to adjust the statistical values for these measures. As shown in Table 2, there were statistically significant improvements across all six measures. For both RWB Discrepancy and EWB Discrepancy and both measures of alcohol problems, there were significant improvements from pre-treatment to post-treatment and from pre-treatment to follow-up, but not from post-treatment to follow-up. BSI Depression and BSI Anxiety scores did not change significantly from pre-treatment to post-treatment, but significant decreases on both were observed from pre-treatment to follow-up. A significant reduction in the BSI permission has been granted for this version to appear in e-Publications@Marquette. [Publisher's Name] does not grant permission for this article to be further copied/distributed or hosted elsewhere without the express permission from [Publisher's Name].] 
NOT THE PUBLISHED VERSION; this is the author's final, peer-reviewed manuscript. The published version may be accessed by following the link in the citation at the bottom of the page.

Depression score was also demonstrated from post-treatment to follow-up.

Table 2. Changes in RWB Discrepancy, EWB Discrepancy, AUDIT, DrInC, BSI Depression, and BSI Anxiety Scores.

\begin{tabular}{|c|c|c|c|c|c|c|c|c|}
\hline \multicolumn{2}{|c|}{ Pre-Treatment } & \multicolumn{3}{|c|}{ Post-Treatment } & \multicolumn{3}{|c|}{ Follow-Up } & \multirow[b]{2}{*}{$\begin{array}{l}\text { Partial } \\
\eta^{2}\end{array}$} \\
\hline & $\mathbf{M}$ & SD & $\mathbf{M}$ & SD & $\mathbf{M}$ & SD & $F(d f)$ & \\
\hline $\begin{array}{l}\text { RWB } \\
\text { Discrepancy }\end{array}$ & $10.51^{a}$ & 10.01 & $5.30^{\mathrm{b}}$ & 10.06 & $6.25^{\mathrm{b}}$ & 8.69 & $12.30(2,106)^{* * *}$ & .18 \\
\hline $\begin{array}{l}\text { EWB } \\
\text { Discrepancy }\end{array}$ & $16.71^{\mathrm{a}}$ & 12.16 & $11.86^{\mathrm{b}}$ & 11.84 & $10.41^{\mathrm{b}}$ & 10.91 & $11.53(1.68,90.45)^{* * *}$ & .18 \\
\hline AUDIT & $18.78^{a}$ & 7.20 & $5.00^{\mathrm{b}}$ & 5.71 & $5.13^{b}$ & 5.90 & $163.34(1.42,76.74)^{* * *}$ & .75 \\
\hline DrInC & $48.50^{\mathrm{a}}$ & 24.98 & $33.96^{\mathrm{b}}$ & 21.10 & $32.56^{\mathrm{b}}$ & 19.19 & $19.73(2,106)^{* * *}$ & .27 \\
\hline $\begin{array}{l}\text { BSI } \\
\text { Depression }\end{array}$ & $11.20^{\mathrm{a}}$ & 4.42 & $10.24^{a}$ & 4.80 & $8.51^{\mathrm{b}}$ & 3.27 & $7.04(1.56,84.12)^{* *}$ & .12 \\
\hline BSI Anxiety & $10.09^{a}$ & 4.09 & $9.40^{a}$ & 4.50 & $8.49^{b}$ & 2.83 & $3.97(1.80,91.66)^{*}$ & .07 \\
\hline
\end{tabular}

Note: Scores with different superscript letters ( $a$ or $b$ ) were significantly different on post-hoc paired samples t-tests.

$* \mathrm{p}<.05$

$* * \mathrm{p}<.01$

$* * * p<.001$.

\section{Change in SRF and Improvement in Alcohol Measures}

Separate stepwise multiple regression equations were generated to predict AUDIT and DrInC scores at follow-up using SRF scores. The models are displayed in Table 3 . At the first step, the pretreatment drinking measure and the pre-treatment measures of RWB Discrepancy and EWB Discrepancy were entered. At the second step, post-treatment scores on the three measures were then entered. With regard to the AUDIT at follow-up, the post-treatment AUDIT scores and post-treatment EWB Discrepancy scores were significant predictors in the full regression model. Specifically, higher EWB Discrepancy scores at post-treatment predicted higher AUDIT scores at follow-up. The DrInC score at follow-up was significantly predicted by the pre-treatment and post-treatment DrInC scores and by the EWB Discrepancy scores. To be specific, lower scores (indicating less discrepancy) on the EWB Discrepancy scale at pre-treatment predicted higher DrInC scores at follow-up, whereas higher scores on the EWB Discrepancy scale at post-treatment predicted higher DrInC scores at follow-up.

[Citation Journal/Monograph Title, Vol XX, No. XX (m yyyy): pg. XX-XX. DOI. This article is @ [Publisher's Name] and permission has been granted for this version to appear in e-Publications@Marquette. [Publisher's Name] does not grant permission for this article to be further copied/distributed or hosted elsewhere without the express permission from [Publisher's Name].] 
NOT THE PUBLISHED VERSION; this is the author's final, peer-reviewed manuscript. The published version may be accessed by following the link in the citation at the bottom of the page.

Table 3. RWB Discrepancy and EWB Discrepancy Pre- and Post- Treatment as Predictors of Change in Alcohol Use and Drinking Consequences at Follow-Up.

Model 1

Model 2

\begin{tabular}{|c|c|c|c|c|c|c|}
\hline B & SE B & $\boldsymbol{\beta}$ & B & SE B & $\boldsymbol{\beta}$ & \\
\hline \multicolumn{7}{|c|}{ Dependent Variable: AUDIT at Follow-Up } \\
\hline AUDIT Intake & 0.31 & 0.11 & $0.38^{* *}$ & 0.12 & 0.08 & 0.14 \\
\hline Pre RWB Discrepancy & 0.03 & 0.12 & 0.06 & 0.08 & 0.10 & 0.13 \\
\hline Pre EWB Discrepancy & -0.06 & 0.10 & -0.11 & -0.14 & 0.08 & -0.28 \\
\hline AUDIT End of Treatment & & & & 0.70 & 0.10 & $0.68^{* * *}$ \\
\hline Post RWB Discrepancy & & & & -0.06 & 0.08 & -0.09 \\
\hline Post EWB Discrepancy & & & & 0.14 & 0.06 & $0.28^{*}$ \\
\hline$R^{2} / F$ for change in $R^{2}$ & \multicolumn{3}{|c|}{$.14 / 2.64$} & \multicolumn{3}{|c|}{$.68^{* * *} / 26.87^{* * *}$} \\
\hline
\end{tabular}

Dependent Variable: DrInC at Follow-Up

DrInC Intake $0.420 .100 .55^{* * *} \quad 0.30 \quad 0.11 \quad 0.39^{* *}$

Pre RWB Discrepancy

$\begin{array}{llllll}0.67 & 0.36 & 0.35 & 0.76 & 0.41 & 0.40\end{array}$

Pre EWB Discrepancy

$-0.570 .30-0.36-0.980 .32-0.63^{* *}$

DrInC End of Treatment

$0.28 \quad 0.120 .31^{*}$

Post RWB Discrepancy

$-0.320 .31-0.17$

Post EWB Discrepancy

$0.76 \quad 0.23 \quad 0.31^{* *}$

$\mathrm{R}^{2} / \mathrm{F}$ for change in $\mathrm{R}^{2}$

$.31^{* * *} / 7.29^{* * *}$

$.51^{* *} / 6.42^{* *}$

Note: Pre $=$ Pre-treatment; Post $=$ Post-treatment (end of treatment); Follow-up $=3$ months after end of treatment

$* \mathrm{p}<.05$

$* * \mathrm{p}<.01$

$* * * p<.001$

\section{Change in SRF and Improvement in Psychiatric Measures}

Separate stepwise multiple regression equations were generated to predict BSI Depression and BSI Anxiety scores at follow-up using

[Citation Journal/Monograph Title, Vol XX, No. XX (m yyyy): pg. XX-XX. DOI. This article is @ [Publisher's Name] and permission has been granted for this version to appear in e-Publications@Marquette. [Publisher's Name] does not grant permission for this article to be further copied/distributed or hosted elsewhere without the express permission from [Publisher's Name].] 
SRF scores, and they are displayed in Table 4. As previously, at the first step, pretreatment measures of the psychiatric symptoms, RWB Discrepancy and EWB Discrepancy were entered. At the second step, post-treatment scores on the three measures were entered. For both the depression and anxiety measures, the only significant predictor of the follow-up scores were those respective scores at post-treatment (see Table 4).

Table 4. RWB Discrepancy and EWB Discrepancy Pre- and Post- Treatment as Predictors of Change in Anxiety and Depression Scores at Follow-Up.

Model 1

Model 2

\begin{tabular}{|c|c|c|c|c|c|c|}
\hline B & SE B & $\boldsymbol{\beta}$ & B & SE B & $\boldsymbol{\beta}$ & \\
\hline \multicolumn{7}{|c|}{ Dependent Variable: BSI Anxiety at Follow-Up } \\
\hline BSI Anxiety Intake & 0.19 & 0.10 & 0.27 & 0.12 & 0.09 & 0.17 \\
\hline Pre RWB Discrepancy & -0.04 & 0.06 & -0.13 & $3-0.01$ & 0.06 & -0.03 \\
\hline Pre EWB Discrepancy & 0.07 & 0.05 & 0.29 & 0.02 & 0.05 & 0.07 \\
\hline BSI Anx. End of Treatment & & & & 0.30 & 0.08 & $0.48^{* * *}$ \\
\hline Post RWB Discrepancy & & & & -0.03 & 0.05 & -0.11 \\
\hline Post EWB Discrepancy & & & & 0.07 & 0.04 & 0.27 \\
\hline $\mathrm{R}^{2} / \mathrm{F}$ for change in $\mathrm{R}^{2}$ & \multicolumn{3}{|c|}{$.18^{*} / 3.55^{*}$} & \multicolumn{3}{|c|}{$.51^{* * *} / 10.63^{* * *}$} \\
\hline \multicolumn{7}{|c|}{ Dependent Variable: DV = BSI Depression at Follow-Up } \\
\hline BSI Depression Intake & 0.03 & 0.12 & 0.04 & 0.12 & 0.11 & 0.16 \\
\hline Pre RWB Discrepancy & 0.03 & 0.07 & 0.09 & 0.03 & 0.08 & 0.09 \\
\hline Pre EWB Discrepancy & 0.02 & 0.06 & 0.09 & -0.03 & 30.07 & -0.11 \\
\hline BSI Dep. End of Treatment & & & & 0.30 & 0.10 & $0.45^{* *}$ \\
\hline Post RWB Discrepancy & & & & -0.23 & 30.06 & -0.07 \\
\hline Post EWB Discrepancy & & & & 0.07 & 0.06 & 0.25 \\
\hline$R^{2} / F$ for change in $R^{2}$ & & $.04 / .67$ & & $.36^{*}$ & $5^{* * *} / 7.8$ & $87^{* * *}$ \\
\hline
\end{tabular}

[Citation Journal/Monograph Title, Vol XX, No. XX (m yyyy): pg. XX-XX. DOI. This article is @ [Publisher's Name] and permission has been granted for this version to appear in e-Publications@Marquette. [Publisher's Name] does not grant permission for this article to be further copied/distributed or hosted elsewhere without the express permission from [Publisher's Name].] 
NOT THE PUBLISHED VERSION; this is the author's final, peer-reviewed manuscript. The published version may be

Note: Pre $=$ Pre-treatment; Post $=$ Post-treatment

${ }^{*} p<.05$

${ }^{* *} p<.01$

${ }^{* * *} p<.001$

\section{Discussion}

In this study, we evaluated how spiritual and religious functioning (SRF), alcohol-related problems, and psychiatric symptoms change over the course of treatment and follow-up. The study participants were similar in demographic characteristics to typical problem drinkers in outpatient treatment (cf., Hasin, Stinson, Ogburn, \& Grant, 2007). Most had been in treatment previously, and a little less than half met criteria for either a mood or an anxiety disorder. Most of the participants had developed a drinking problem at least a decade before this treatment episode. All reported varying levels of alcohol-related problems in their physical health, interpersonal relationships and self-regard. On average they reported a substantial level of discrepancy between their current SRF and what they reported as their "preferred" SRF (see also S. M. Saunders et al., 2007). Finally, there was no difference in RWB Discrepancy between those who completed treatment and those who did not; however, completers reported significantly higher EWB Discrepancy prior to treatment than non-completers. This initial discrepancy, perhaps indicative of general life distress or greater desire for change, may motivate individuals to invest more into their treatment or take their treatment more seriously.

Over the course of treatment, the discrepancy between participants' ratings of their current experience of their SRF and their ratings of their preferred SRF decreased significantly. We take this to indicate that their SRF improved, as has been found by other researchers (Robinson et al., 2007; Tonigan, 2007). During this same time frame, significant improvement in alcohol-related issues also occurred, as both hazardous drinking (measured via the AUDIT) and the negative consequences of drinking behavior (measured via the DrInC) decreased. Although measures of psychiatric symptoms also improved significantly, they did so within a different time frame (i.e., not during treatment, but rather from post-treatment to follow-up). These results suggest that there is concurrence between patients' spiritual functioning and their use of alcohol and its negative

[Citation Journal/Monograph Title, Vol XX, No. XX (m yyyy): pg. XX-XX. DOI. This article is (C) [Publisher's Name] and permission has been granted for this version to appear in e-Publications@Marquette. [Publisher's Name] does not grant permission for this article to be further copied/distributed or hosted elsewhere without the express permission from [Publisher's Name].] 
consequences, as these changed at simultaneous measurement points. These results contradict the idea that changes in drinking behavior and problems are associated with spiritual measures because of the latter's influence on emotional distress, and these findings thus support those of Polcin and Zemore (2004).

SRF scores were correlated with the anxiety and depression measures at all three time points. EWB Discrepancy was correlated with both depression and anxiety scores at all the time points, with greater discrepancy associated with higher levels of distress, and relatively high levels of discrepancy on the RWB measure were associated with depression (but not anxiety) at pre-treatment and follow-up. These findings may be related to concerns about the construct validity of this study's primary measure of SRF, the SWBS (Bufford et al., 1991). It has been argued that many measures of spiritual and religious functioning may actually more appropriately be considered measures of mental health (cf. Moreira-Almeida \& Koenig, 2006). Future studies would benefit from measures that are more consistent with widely accepted definitions of spirituality and religion (e.g., Hill \& Pargament, 2003), including the definitions provided earlier. Despite this concern, we note that our measures of SRF predicted change in alcohol-related behavior and problems, but did not predict changes in depression and anxiety. In other words, these results suggest that there is something besides mental health being measured by the SWBS (which was the basis of our measure of SRF) and, further, that it is not improvement in mental health that leads to improved alcohol-related problems.

SRF scores were not significantly correlated (after the correction for multiple statistical tests) with the drinking measures at any of the three time points. Regression analyses indicated that greater EWB Discrepancy at post-treatment predicted greater drinking behavior (measured via the AUDIT) at follow-up. The regression equations also indicated that changes in SRF scores were predictive of changes in alcohol-related problems (measured via the DrInC). Specifically, the results indicated that patients who were relatively satisfied with their existential well-being (i.e., their discrepancy scores were relatively low) at the beginning of treatment had relatively more alcohol-related problems at follow-up. In contrast, patients who entered treatment with relatively high dissatisfaction with their existential well-being, but

[Citation Journal/Monograph Title, Vol XX, No. XX (m yyyy): pg. XX-XX. DOI. This article is (C [Publisher's Name] and permission has been granted for this version to appear in e-Publications@Marquette. [Publisher's Name] does not grant permission for this article to be further copied/distributed or hosted elsewhere without the express permission from [Publisher's Name].] 
whose dissatisfaction decreased over treatment, had relatively fewer problems related to alcohol use at follow-up.

Further research is needed to elucidate the influence of EWB discrepancy on recovery. We found that those with greater EWB discrepancy are more likely to complete treatment and that reduction in EWB discrepancy is related to later improvements in alcohol-related issues. As mentioned before, perhaps this discrepancy is indicative of general life distress or greater desire for change. Individuals with larger discrepancy may be more motivated to change, thus they engage more in treatment and are more likely to see the positive results. Individuals who experience a reduction in discrepancy (that is, an increase in their satisfaction) may then be more motivated to make changes during the course of treatment and to continue to invest in their recovery following the completion of treatment.

The study has several limitations. First, the participants were predominantly white and the sample size was fairly small. The former issue limits the external validity of the study, and the latter issue precluded some statistical analyses (e.g., SEM) that might have clarified the associations between the variables of interest. Also, the selection criteria for the study specified that participants had to have both completed treatment and participated in a research interview approximately three months after treatment termination. This introduced a self-selection bias, that is, those who were eligible for the study were most likely to have "succeeded" at treatment. Finally, similar to many treatment programs for alcohol problems, treatment explicitly focused on the outcome variables of interest, that is, spirituality, drinking and emotional functioning.

Despite these limitations, the study results suggest that the associations between the primary constructs of interest are worth further study. The results suggest that changes in spiritual functioning lead to later changes in alcohol misuse and associated problems, and that this is not entirely related to improved mental health. Additional studies with larger, more representative samples would allow greater specification of the association between spirituality, alcohol problems, and emotional distress. Specifically, meditational studies that can account for the timing of changes in alcohol-related issues and comorbid psychiatric illnesses will help elucidate exactly how changes

[Citation Journal/Monograph Title, Vol XX, No. XX (m yyyy): pg. XX-XX. DOI. This article is @ [Publisher's Name] and permission has been granted for this version to appear in e-Publications@Marquette. [Publisher's Name] does not grant permission for this article to be further copied/distributed or hosted elsewhere without the express permission from [Publisher's Name].] 
in SRF relate to other clinically-relevant changes in patients.

Furthermore, as there is such a high rate of relapse within this population, studies are needed to examine the relationships of SRF, alcohol-related issues, and psychiatric functioning over much longer periods of time.

\section{Acknowledgments}

The authors wish to thank Maxwell D. McNally for his thoughtful review of this manuscript.

\section{Footnotes}

Publisher's Disclaimer: The following manuscript is the final accepted manuscript. It has not been subjected to the final copyediting, fact-checking, and proofreading required for formal publication. It is not the definitive, publisher-authenticated version. The American Psychological Association and its Council of Editors disclaim any responsibility or liabilities for errors or omissions of this manuscript version, any version derived from this manuscript by $\mathrm{NIH}$, or other third parties. The published version is available at www.apa.org/pubs/journals/adb

\section{Contributor Information}

Melissa L. Miller, Graduate student pursuing her doctorate in clinical psychology at Marquette University.

Stephen M. Saunders, Professor and the Director of Clinical Training at Marquette University.

\section{References}

Allen JP, Litten RZ, Fertig JB, Babor T. A review of research on the Alcohol Use Disorders Identification Test (AUDIT) Alcoholism: Clinical and Experimental Research. 1997;21:613-619.

Benda $B$. The effect of religion on adolescent delinquency revisited. Journal of Research in Crime and Delinquency. 1995;32:446466.

Bohn MJ, Babor TF, Kranzler HR. The Alcohol Use Disorders Identification Test (AUDIT): validation of a screening instrument for use in medical settings. Journal of Studies in Alcohol. $1995 ; 56: 423-32$.

[Citation Journal/Monograph Title, Vol XX, No. XX (m yyyy): pg. XX-XX. DOI. This article is @ [Publisher's Name] and permission has been granted for this version to appear in e-Publications@Marquette. [Publisher's Name] does not grant permission for this article to be further copied/distributed or hosted elsewhere without the express permission from [Publisher's Name].] 
Boulet J. Reliability and validity of the Brief Symptom Inventory. Psychological Assessment. 1991;3:433-437.

Bufford RK, Paloutzian RF, Ellison CA. Norms for the spiritual wellbeing scale. Journal of Psychology and Theology. $1991 ; 19(1): 56-70$.

Chatters LM, Bullard KM, Taylor RJ, Woodward AT, Neighbors HW, Jackson JS. Religious participation and DSM-IV disorders among older African Americans: findings from the National Survey of American Life. American Journal of Geriatric Psychiatry. 2008; 16:957-65.

Chatters LM. Religion and health: Public health and practice. Annual Review of Public Health. 2000;21:335-367.

Derogatis LR, Spencer PM. Brief Symptom Inventory (BSI): Administration and Procedures, Manual 1. Baltimore: Clinical Psychosomatic Research, Johns Hopkins University School of Medicine; 1982.

Engs RC, Hanson DJ, Diebold BA. The drinking patterns and problems of a national sample of college students. Journal of Alcohol and Drug Education. 1996;41:13-33.

First MB, Spitzer RL, Gibbon M, Williams JBW. Structured Clinical Interview for DSM-IV Axis I Disorders, Clinician Version (SCIDCV) Washington, D.C.: American Psychiatric Press, Inc; 1996.

Hardesty $\mathrm{PH}$, Kirby KM. Relation between family religiousness and drug use within adolescent peer groups. Journal of Social Behavior and Personality. 1995;10:421-430.

Hasin DS, Stinson FS, Ogburn E, Grant BF. Prevalence, correlates, disability, and comorbidity of DSM-IV alcohol abuse and dependence in the United States: Results from the National Epidemiologic Survey on Alcohol and Related Conditions. Archives of General Psychiatry. 2007;64:830-842.

Hill PC, Pargament KI. Advances in the conceptualization and measurement of religion and spirituality: Implications of physical and mental health research. American Psychologist. 2003; 58:64-74.

Kendler KS, Gardner CO, Prescott CA. Religion, psychopathology, and substance use and abuse: A multimeasure, geneticepidemiologic study. American Journal of Psychiatry. 1997; 154:322-329. permission has been granted for this version to appear in e-Publications@Marquette. [Publisher's Name] does not grant permission for this article to be further copied/distributed or hosted elsewhere without the express permission from [Publisher's Name].] 
Kessler RC, Nelson CB, McGonagle KA, Edlund MJ, Frank RG, Leaf PJ. The epidemiology of co-occurring addictive and mental disorders: implications for prevention and service utilization. American Journal of Orthopsychiatry. 1996;66:17-31.

Mathew RJ, Georgi J, Wilson WH, Mathew V. A retrospective study of the concept of spirituality as understood by recovering individuals. Journal of Substance Abuse Treatment. 1996;13:67-73.

McCullough ME, Hoyt WT, Larson DB, Koenig HG, Thoresen C. Religious involvement and mortality: A meta-analytic review. Health Psychology. 2000;19:211-222.

Miller WR, Tonigan JS, Longabaugh R. Project MATCH Monograph Series. Vol. 4. Rockville, MD: National Institute on Alcohol Abuse and Alcoholism; 1995. The Drinker Inventory of Consequences (DrInC): An instrument for assessing adverse consequences of alcohol abuse. Test manual.

Mofidi M, DeVellis RF, Blazer DG, DeVellis BM, Panter AT, Jordan JM. Spirituality and depressive symptoms in a racially diverse U.S. sample of community-dwelling adults. The Journal of Nervous \& Mental Disease. 2006;194:975-977.

Montgomery HA, Miller WR, Tonigan JS. Does Alcoholics Anonymous involvement predict treatment outcome? Journal of Substance Abuse Treatment. 1995;12:241-246.

Moreira-Almeida A, Koenig HG. Retaining the meaning of the words religiousness and spirituality: A commentary on the WHOQOL SRPB group's "A cross-cultural study of spirituality, religion, and personal beliefs as components of quality of life" Social Science \& Medicine. 2006;63:843-845. doi: 10.1016/j.socscimed.2006.03.001.

Nealon-Woods M, Ferrari JR, Jason LA. Twelve-step program use among Oxford House residents: Spirituality or social support in sobriety? Journal of Substance Abuse. 1995; 7:311-318.

Paloutzian RF, Ellison CW. Loneliness, spiritual well-being, and the quality of life. In: Peplau LA, Pearlman D, editors. Loneliness: A sourcebook of current theory, research and therapy. New York: Wiley; 1982. pp. 224-237.

Pargament KI, Koenig HG, Tarakeshwar N, Hahn J. Religious coping methods as predictors of psychological, physical and spiritual outcomes among medically ill elderly patients: A two-year permission has been granted for this version to appear in e-Publications@Marquette. [Publisher's Name] does not grant permission for this article to be further copied/distributed or hosted elsewhere without the express permission from [Publisher's Name].] 
longitudinal study. Journal of Health Psychology. 2004;9:713730.

Polcin DL, Zemore S. Psychiatric severity and spirituality, helping, and participation in alcoholics anonymous during recovery. American Journal of Drug \& Alcohol Abuse. 2004;30:577-592.

Project MATCH Research Group. Matching alcoholism treatments to client heterogeneity: Project MATCH posttreatment drinking outcomes. Journal of Studies on Alcohol. 1997;58:7-29.

Robinson EAR, Cranford JA, Webb JR, Brower KJ. Six-month changes in spirituality, religiousness, and heavy drinking in a treatmentseeking sample. Journal of Studies on Alcohol and Drugs. 2007;68:282-290.

Saunders JB, Aasland OG, Babor TF, de la Fuente JR, Grant M. Development of the Alcohol Use Disorders Identification Test (AUDIT) Addiction. 1993;88:791-804.

Saunders SM, Wright V, Kuras L. Measuring the discrepancy between current and ideal spiritual and religious functioning in problem drinkers. Psychology of Addictive Behaviors. 2007;21:404-408. Tonigan JS. Spirituality and Alcoholics Anonymous. Southern Medical Journal. 2007; 100:437-440. doi: 10.1097/SMJ.0b013e31803171ef.

Waite PJ, Hawks SR, Gast JA. The correlation between spiritual wellbeing and. health behaviors. American Journal of Health Promotion. 1999;13:159-162.

Zemore SE, Kaskutas LA. Helping, spirituality and Alcoholics Anonymous in recovery. Journal of Studies on Alcohol. 2004;65:383-391. 